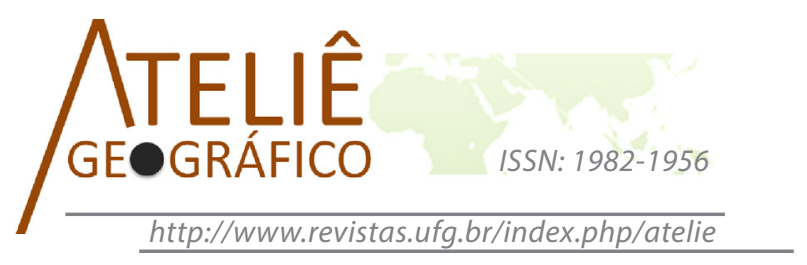

\title{
Expansão urbana recente em Altamira (PA) Novas tendências de crescimento a partir da instalação da UHE Belo Monte
}

\author{
Recent urban expansion in Altamira - (Pará State) \\ New growth trends after implementation of the \\ hydroelectric plant of Belo Monte
}

\section{Expansión urbana reciente en Altamira (Pará) Nuevas tendencias de crecimiento después de la instalación de la central hidroeléctrica de Belo Monte}

\author{
José Queiroz de Miranda Neto \\ Universidade federal do Pará - UFPA \\ mirandaneto@ufpa.br \\ José Antônio Herrera \\ Universidade Federal do Pará - UFPA \\ herrera@ufpa.br
}

\begin{abstract}
Resumo
Este artigo analisa o processo de expansão urbana recente em Altamira - PA, de modo a verificar as novas tendências de crescimento a partir da instalação da usina hidrelétrica de Belo Monte. São utilizados como bases teóricas os conceitos ligados à morfologia urbana e à produção social do espaço urbano. A expansão urbana recente se constitui a partir de fatores articulados ao processo de instalação da usina hidrelétrica, onde se verifica um crescimento acelerado da malha urbana em várias direções, respeitando o sentido das vias estruturantes. Tal crescimento chega a ultrapassar $50 \%$ e se dá a partir de novas instalações urbanas para habitação e uso coletivo, públicas e privadas, que alteram o desenho da cidade, sua paisagem e estrutura urbana. Nesse novo cenário, cabe destaque ao papel dos agentes imobiliários e do poder público, bem como da empresa Norte Energia S.A como indutora de processos e agente ordenador do território.
\end{abstract}

Palavras-chave: Expansão urbana, morfologia, Altamira, Belo Monte. 


\begin{abstract}
Abstrac
This article analyzes the process of recent urban expansion in Altamira, Pará State, in order to check for new growth trends after the implementation of the hydroelectric plant of Belo Monte. The concepts related to urban morphology and social production of urban space are used as theoretical basis to this study. The recent urban expansion is composed by factors related to the hydroelectric plant implementation process, which shows a rapid growth of the urban mesh in several directions, respecting the way of structuring roads. Such growth exceeds $50 \%$ and it happens by means of public and private new urban facilities for housing and collective use that alter the design of the city, its landscape and urban infrastructure. In this new scenario, it is highlighted the real estate agents', government's, and Norte Energia corporation's roles, being the former one considered an originator territory agent and responsible for inducing this processes.

Keywords: urban expansion, morphology, Altamira, Belo Monte.

Resumen

En este artículo se analiza el proceso de reciente expansión urbana en AltamiraPA, con el fin de comprobar si hay nuevas tendencias de crecimiento después de la instalación de la central hidroeléctrica de Belo Monte. Se utilizan como base teórica los conceptos relacionados con la morfología urbana y la producción social del espacio urbano. La reciente expansión urbana se constituye a partir de factores relacionados con el proceso de instalación de la planta hidroeléctrica, donde hay un rápido crecimiento de la red urbana en varias direcciones, respetando el modo de estructuración de las carreteras. Este crecimiento es superior al 50\% y se produce a partir de nuevos equipamientos urbanos para viviendas y uso colectivo, públicos y privados, que alteren el diseño de la ciudad, su paisaje y la estructura urbana . En este nuevo escenario, hay que destacar el papel de los agentes de bienes raíces, el gobierno y también del Norte Energia S.A, que induce procesos y articula el territorio .
\end{abstract}

Palabras claves: expansión urbana, morfología, Altamira, Belo Monte.

\title{
Introdução
}

Com esse trabalho se pretende analisar o processo de expansão urbana em Altamira - PA, de modo a verificar as novas tendências de crescimento a partir da instalação da usina hidrelétrica de Belo Monte, licenciada no início de 2010. Seguindo esse objetivo, serão utilizados como bases teóricas os conceitos ligados à morfologia urbana e à produção social do espaço urbano, conforme a direção metodológica dos autores referenciados, como Castells (1983), Harvey (1980) e Santos (2012).

A pesquisa possui como motivação a necessidade de se entender o processo acelerado de expansão da cidade de Altamira no período de 2010 a 2014 e as previsões para os anos subsequentes. Para isso, foi necessário entender o histórico de ocupação da cidade a partir do processo de integração nacional pós década de 1960, com consequência direta na evolução populacional e no crescimento da malha urbana. A cidade em questão passou por diferentes surtos de crescimento, muitos dos quais ligados à decadência da política de colonização dirigida e o consequente êxodo rural. Contudo, o período 
de crescimento atual difere dos anteriores, pois se conforma a partir de fatores novos, especialmente articulados ao processo de instalação da usina hidrelétrica.

A análise dos dados demonstra um crescimento acelerado da malha urbana em várias direções, respeitando o sentido das vias estruturantes. Tal crescimento chega a ultrapassar 50\% da malha urbana de 2010 e se dá a partir de novas instalações urbanas para habitação e uso coletivo, públicas e privadas, que alteram o desenho da cidade, sua paisagem e estrutura urbana. Cabe destaque, nesse novo contexto, ao papel dos agentes imobiliários e do poder público, especialmente nas esferas federal e municipal. Porém, é significativo o papel da Norte Energia S.A como indutora de processos e agente ordenador do território, com capacidade de mobilizar fluxos e intervir em diversos tipos de relacionamentos no contexto da cidade.

\section{Morfologia urbana e os estudos sobre o crescimento das cidades}

O campo de estudo da morfologia urbana se deu em resposta ao crescente processo de urbanização em meados do séc. XX. Nesse momento, as cidades antigas, menores e mais harmônicas dão lugar às grandes cidades, funcionalmente complexas e diversificadas. No mundo desenvolvido, as grandes cidades industriais dos EUA e Grã-Bretanha passam por mudanças internas, dadas as tendências de descentralização relativa da população e a presença do carro particular como modo dominante de transporte (CLARK, 1991). Na América Latina, Ásia e África, as cidades que antes eram centros portuários ou mineradores, ligados ao colonialismo ocidental, passaram por uma reestruturação funcional devido à industrialização pretérita, tendo como resultado uma urbanização acelerada. No Brasil, por exemplo, entre 1920 e 1940 a taxa de urbanização cresceu de 10,7\% para 31,24\% (SANTOS, 2009). Tal quadro é suficiente para se considerar o século XX como o século da urbanização, no qual se constata a proeminência da cidade em relação ao campo.

Devido à ampliação da urbanização em escala mundial, tem-se um momento fértil para o desenvolvimento dos estudos empenhados em uma construção metodológica da estrutura espacial das cidades. A morfologia urbana surgiu, então, como uma das respostas à necessidade de se entender os aspectos relacionados à forma urbana em seus diversos níveis e resoluções, desde o edifício e seu lote até o quarteirão, a cidade e a região (MOUDON, 1997). Trata-se, ainda, de um campo disciplinar com variações em sua concepção e com escolas de pensamento delimitadas, que não se afirma somente entre geógrafos, arquitetos e urbanistas, mas entre todos aqueles ligados à concepção ou ao planejamento das formas urbanas. Tentando sintetizar suas diferenciações internas, Lamas (2004, p. 38) afirma que "a morfologia urbana é a disciplina que estuda o objeto a forma urbana - nas suas características exteriores, físicas, e na sua evolução no tempo".

No caso da Geografia, a principal difusão desses estudos se deu por intermédio da Escola de Chicago, conforme apontam Whitacker e Miyazaki (2013, p. 4) "as contribuições se deram na produção de modelos interpretativos que levavam em conta as formas espaciais decorrentes dos chamados processos ecológicos de concentração, centralização/descentralização, invasão-sucessão e segregação". Muitas dessas análises 
partiam de uma matriz interpretativa baseada na biologia e demais ciências da natureza, de modo que o crescimento das cidades é comparado ao desenvolvimento dos seres vivos. Tal explicação fundamenta o pensamento da chamada ecologia urbana, tendo como principais representantes Burgess e Mackenzie, os quais naturalizam o conjunto de relações inerentes à estrutura urbana.

Embora grande parte desses estudos esteja ancorada no neopositivismo e na abordagem sistêmica, há também aqueles que se permitem um olhar crítico sobre as formas. A partir da década de 1970, através da interveniência de importantes intelectuais marxistas como Henri Lefebvre, Emanuel Castells e David Harvey, tem-se uma diferente perspectiva sobre a relação entre os homens e as formas espaciais. Nesse sentido, o espaço urbano não é organizado por forças seletivas, distributivas e acomodativas, como se propunha pelos intelectuais da abordagem ecológica, mas é estruturado a partir dos processos sociais, os quais podem ser compreendidos somente e a partir da análise histórica dos diferentes modo-de-produção (CASTELLS, 1983). Não há, contudo, uma mudança na definição clássica de morfologia urbana, mas uma reorientação de vetores, variáveis e abordagens estatísticas. Em "A justiça social e a cidade", Harvey (1980) elenca elementos essenciais que são capazes de alterar a dinâmica interna das cidades e modificar seu contorno, limites ou a direção de seu crescimento, a exemplo da distribuição da renda real, das mudanças no valor de uso do solo urbano e da circulação do excedente. A forma da cidade é, portando, definida a partir de uma sociedade dividida em classes e a organização dos elementos do espaço dependem do rendimento dos seus habitantes, condicionado por relações desiguais de produção.

No caso de países subdesenvolvidos, Santos (2012, p. 189) entende que a forma atribuída ao tecido urbano pode ser aferida "pela análise diferencial de um certo número de características do habitat e dos serviços de cada bairro, assim como pelas trocas entre as diferentes frações do tecido urbano". Nesse sentido, é possível perceber a existência de diversas cidades dentro de uma cidade, diferenciadas de acordo com a condição econômica de seus habitantes, das quais se podem destacar alguns setores, como a) os bairros ricos: relativamente homogêneos e onde se concentra a maioria dos equipamentos urbanísticos; b) bairros pobres da periferia: áreas populares em situação distinta do centro, mas que não se comparam com favelas; e c) as favelas: áreas de maior carência de equipamentos urbanísticos, de concentração da população mais pobre. $\mathrm{O}$ espaço da cidade compreende, nesse caso, aos diferentes usos da terra justapostos entre si, o que resulta em um espaço dividido, fragmentado e, ao mesmo tempo, articulado (CORRÊA, 2003).

Neste artigo, a proposta de análise do crescimento urbano em Altamira segue o caminho adotado pela abordagem crítica da morfologia urbana, onde as formas espaciais são consideradas como resultado e condição das relações sociais de produção. Por esse viés, as direções de crescimento da cidade estão na base dos processos socioespaciais determinados pela oposição de classes, uma vez que a relação localização/acessibilidade é produzida quase sempre favoravelmente aos grupos econômicos mais fortes, em detrimento da população de menor poder aquisitivo. Villaça (2001, p. 78) faz uma breve análise da relação entre o solo urbano como valor de troca e conclui que: 
Os pontos do espaço intra-urbano condicionam a participação do seu ocupante tanto na força produtiva social representada pela cidade como na absorção, através do consumo, das vantagens da aglomeração. Esse "relacionamento" se dá de diversas formas e por meio de diversos fluxos - o transporte de mercadorias, de consumidores, de força de trabalho ou as comunicações - , os quais tem importância e papéis diferentes conforme se trate de espaço regional ou intra-urbano.

Desse modo, a estrutura espacial da cidade advém das transformações em seus pontos, que são marcos de referência na conjuntura urbana, baseados na localização das formas espaciais e seu significado em relação à cidade como um todo. Assim, seus valores, atributos, preços e formas de uso podem variar a partir de quando se tornam mais ou menos acessíveis. De acordo com Villaça (2001) existe uma relação muito próxima entre a valorização de determinados pontos e os eixos de transporte como avenidas, rodovias de integração, ferrovias, túneis, etc. Assim, para se ter uma dimensão das direções de crescimento da cidade é importante conceber de que forma tais eixos viários estão estruturados. Isso não quer dizer que estes sejam os causadores da expansão das cidades, mas que geram a valorização dos terrenos (relação valor-trabalho) em função melhoria da acessibilidade. Deve-se considerar, também, a relação entre as distâncias entre determinados pontos a partir do tipo de veículo que se utiliza. Nesse caso, para quem depende de transporte público há uma acessibilidade diferenciada se comparado com aqueles que possuem transporte particular.

As direções de crescimento da cidade tendem, portando, a seguir a lógica de estruturação das vias regionais (rodovias ou ferrovias) sendo este o principal padrão verificado por Villaça (2001, p. 80) para o caso do Brasil, ao afirmar que:

Sendo os transportes intra-urbanos os maiores determinantes das transformações dos pontos, as vias de transporte têm enorme influência não só no arranjo interno das cidades, mas também sobre os diferenciais de expansão urbana.

No caso das cidades da Amazônia, principalmente aquelas desenvolvidas a partir do processo de ocupação nos anos 60 e 70, a estruturação urbana com base nos eixos de integração rodoviária foi previamente concebida pelo governo militar. Segundo Becker (1997, p. 55) "as rodovias são os eixos da nova circulação, em detrimento da via fluvial, deslocando o sitio dos núcleos do vale para a terra firme ou revivendo cidades que comandavam a economia e a circulação dos grandes vales". As cidades que passaram a se localizar na confluência entre o rio e rodovia, como Marabá e Altamira, já dotadas de equipamentos urbanos funcionais, recebem destaque nesse processo. A rodovia Transamazônica (BR-230), criada com o objetivo de integrar a região ao restante do país, passa a ser o eixo de ligação entre centros urbanos antigos e novos, que determina não apenas a estruturação da rede de cidades, mas também delineia a própria forma interna das mesmas. A seguir, veremos de que maneira o crescimento da cidade de Altamira, após a década de 60 , tendeu a repetir a dinâmica de crescimento verificado no resto do país, com deslocamento dos vetores de crescimento para o eixo da rodovia. 


\section{Crescimento histórico-espacial da cidade de Altamira}

A cidade de Altamira surgiu em decorrência do processo de colonização da Amazônia no final do século XVII. Através da penetração das primeiras missões jesuíticas no médio rio Xingu, várias edificações foram erigidas em alguns pontos estratégicos da extensa rede de drenagem, dentre as quais templos religiosos, colégios e habitações necessárias às atividades da igreja católica. De acordo com Umbuzeiro e Umbuzeiro (2012), o grande desafio para acessar aquela área eram as cachoeiras da volta grande, "onde o rio é cortado por uma grande quantidade de ilhas, separadas por inúmeros canais estreitos, que dificultavam a navegação de maior calado, circulando apenas pequenas embarcações” (p. 31). Com a ajuda de indígenas, os missionários ultrapassaram as cataratas e chegaram à foz dos atuais Igarapés Panelas e Ambé, onde instalaram a povoação que, posteriormente, daria origem à Vila de Altamira.

Criado em 6 de novembro de 1911 em decorrência do desmembramento do município de Sousel, o município de Altamira (na época Alta-Mira) tinha como referência a Vila de mesmo nome, que é transformada oficialmente em cidade-sede somente em 1917, tornando-se referência para as demais localidades da área. No período, especialmente entre o final do século XIX até 1950 (contexto do boom da borracha), a principal atividade desenvolvida era a produção de uma borracha de menor qualidade denominada caucho. Umbuzeiro e Umbuzeiro (2012) fazem a seguinte referência à produção da época

A produção extrativista ultrapassou em 1959 mais de um bilhão de cruzeiros. A produção de caucho (uma borracha de menor qualidade) foi de 936 milhões e a de borracha foi de 337 milhões de cruzeiros. A castanha-do-pará ultrapassou 787 toneladas. Em 1958 existiam 5 estabelecimentos industriais com 12 empregados, em 1960 haviam aumentado para 7 estabelecimentos (p. 145).

O significado deste centro urbano em relação às outras localidades da região não era de grande expressão até o final da década de 1950, por um lado devido ao relativo isolamento da cidade em função da presença das cachoeiras na região da Volta Grande do Xingu, que dificultava a navegação. Por outro lado, a baixa produtividade econômica aliada à incapacidade de se tornar um entreposto comercial de importância fazia de Altamira apenas uma entre as demais localidades de mesmo nível situadas na hinterlândia da rede dendrítica amazônica. Na época (1950), a população urbana era 1.809 habitantes, sendo a população rural três vezes maior (IBGE, 2010). Nesse caso, o crescimento expressivo da cidade de Altamira, sua configuração enquanto polo urbano bem como sua diversificação funcional só se tornaram possíveis com processo de integração da Amazônia ao resto do país pela via rodoviária.

A forte migração inter-regional de trabalhadores na abertura das frentes de expansão, sobretudo ao longo da rodovia Transamazônica (BR-230), se deu a partir da década de 60 sob a égide do Governo Militar. Inaugurada em 1972, a rodovia fazia parte da ação geopolítica do governo brasileiro para a Amazônia com vistas a explorar novas oportunidades econômicas. Segundo Alonso e Castro (2006, p. 167). 
A colonização na Transamazônica, contrariamente a do Centro Oeste, que foi caracterizada pela expansão a partir de vilas e cidades já existentes, realizou-se através da construção de um eixo rodoviário de leste a oeste e do desenvolvimento de centros como Altamira, Itaituba, Marabá, todos eles base de apoio à atividade extrativa. Em 1970, a criação do PIN Altamira foi um marco na definição de um modelo de colonização no qual a ação do Estado inova ao definir um padrão de ocupação de fronteira a partir da facilidade de acesso livre aos recursos. A alteração sucessiva da dinâmica regional reflete a relação conflituosa que decorre desta ação e a emergência de mobilizações, em especial na fronteira agrícola do PIC Altamira.

A colonização dirigida foi uma das estratégias de maior relevância no processo de ocupação territorial da Amazônia, principalmente com a atuação do Instituto Nacional de Colonização e Reforma Agrária (INCRA), criado em 1970. O INCRA tinha o papel de viabilizar os assentamentos de colonos na Transamazônica com a promessa de garantir assistência técnica e financeira. Até a década de 1980, a maior área ocupada (3.759.500 ha) e o maior número de famílias assentadas pelo programa (6 mil) estão situadas no município de Altamira (BECKER, 1997). As características do processo de colonização na região podem ser entendidas pela descrição abaixo:

A implantação do projeto integrado de colonização de Altamira estabeleceu um padrão em que se associava o assentamento de colonos nos lotes rurais e em lotes urbanos no plano urbano-rural previsto. O padrão de colonização estabelecido prioritariamente era destinado a pequenos proprietários e o assentamento se faria na faixa de $10 \mathrm{Km}$ das margens esquerda e direita da rodovia principal, a BR-230 ou Transamazônica. As terras destinadas aos colonos foram divididas em lotes de 100 ha tanto na faixa marginal $(500 \mathrm{~m} \mathrm{x}$ $2.000 \mathrm{~m}$ ) quanto ao longo das estradas vicinais $(400 \mathrm{~m} \times 2.500 \mathrm{~m})$. O projeto previa, também, a construção a cada cinco quilômetros de uma estrada vicinal e um travessão com duplo objetivo: penetração no interior do território e acesso aos lotes mais ao fundo; permitir o escoamento da produção agropecuária. Cerca de 6.300 famílias foram assentadas pelo projeto.

Um sistema urbano projetado completava o projeto. A colonização ao longo da Transamazônica previa um sistema composto de três pequenos núcleos urbanos hierarquicamente posicionados e com funções diferentes e complementares: Rurópolis, Agrópolis e Agrovilas. No PIC - Altamira, entretanto, baseado em sistema que teria como ponto central de apoio uma cidade pré-existente, foram construídas, apenas, as agrópolis e agrovilas. (ELETRONORTE, 2009, p. 18)

No conjunto desse processo, temos o primeiro período de crescimento acelerado da população urbana de Altamira. Entre 1950 e 1970, época em que se instalam as bases do processo de colonização, a população saltou de 1.809 para 5.734, respectivamente, crescendo três vezes mais. Contudo, a população urbana somente ultrapassa a população rural entre 1970 e 1980, passando de 5.734 para 29.911 habitantes, crescendo cinco vezes mais, enquanto que a população rural passa de 9.611 para 19.598 , crescendo duas vezes mais. A partir de então, os ritmos de crescimento urbano e rural tomam direções opostas, conforme se observa na figura 1. 


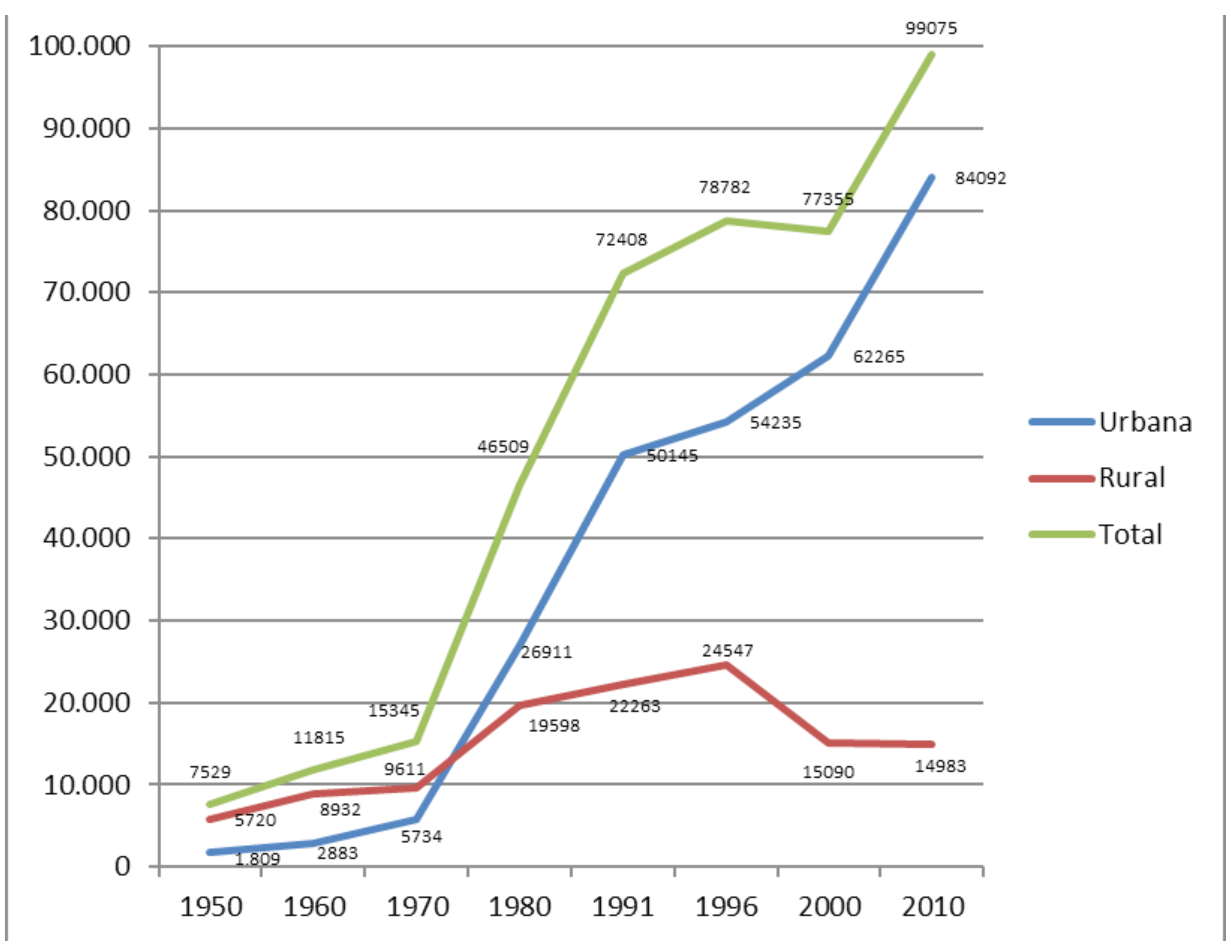

Figura 1. Evolução da população do município de Altamira entre 1950 e 2010.

Fonte: IBGE (2010)

Segundo Becker (1997) existe uma particularidade em relação à expansão da fronteira urbana na Amazônia relacionada à mobilização do trabalho ao afirmar que "uma fronteira urbana é a base logística para o projeto de rápida ocupação da região, acompanhando e mesmo se antecipando à expansão de várias frentes. Trata-se de uma feição original da fronteira contemporânea" (BECKER, 1997, p. 44). Motivado pela abertura dessas novas frentes de trabalho, o processo de urbanização aconteceu de forma mais rápida que o resto do país, uma vez que esteve fortemente associada ao processo migratório. No caso de Altamira, que foi um dos focos da fronteira agrícola na região, a cidade serviu, em um primeiro momento, como centro financeiro e comercial, além de núcleo para concentração das atividades de gestão e instalação dos aparelhos de Estado.

O processo de colonização viabilizado pelo INCRA havia garantido aos trabalhadores a manutenção das atividades no campo, com doação de 100 hectares para cada colono, além da instalação de uma estrutura que incluía a criação de agrovilas a cada $10 \mathrm{~km}$ e de agrópoles a cada $50 \mathrm{~km}$ (PANDOLFO, 1994). Contudo, a partir de 1973, com a crise do Petróleo e a reorientação da política estatal para a Amazônia, houve a desativação do modelo de colonização empregado e o resultado foi o rápido aumento da população urbana de Altamira e de outros municípios da Amazônia oriental. Tal crescimento esteve diretamente influenciado pelo processo de migração interna 
resultante da expropriação e dificuldades de acesso a terra. Conforme se observa no Gráfico 01, a partir de 1980, quando os efeitos da desarticulação no campo passam a ser perceptíveis na cidade, há um aumento significativo da população urbana, ao passo que a população rural cresce em ritmo bem menor. Esse rápido crescimento marcou o novo papel de Altamira, como núcleo de absorção da população migrante, como destaca Alonso e Castro (2006, p. 190)

É importante destacar que a década de 1980 foi um período em que muitos colonos abandonaram seus lotes na Transamazônica, sendo a cidade de Altamira uma das principais escolhas de destino desses migrantes. Nesse período, novos bairros aparecem, contudo a estrutura da cidade era deficiente.

A década de 1980 representou para a cidade de Altamira um novo período de redefinição de sua forma urbana, marcada pela implantação de novos bairros periféricos, muitos dos quais sem infraestrutura adequada. Essas áreas são ocupadas por "migrantes sem terra assalariados urbano-rurais, bem como no centro ou próximo a ele como loteamentos espontâneos ocupados por ex-colonos empregados no terciário" (BECKER, 1985 , p. 365). Dada a incapacidade do núcleo urbano em atender à grande quantidade de pessoas provenientes do êxodo rural, os resultados desse processo se revelaram problemáticos, com implicações na qualidade dos serviços essenciais e ampliação das mazelas sociais. Grande parte das famílias fixou residência em áreas periodicamente alagadas próximas aos igarapés Altamira e Ambé. Alguns desses contingentes populacionais mantem o vínculo reprodutivo com atividades agrícolas, enquanto outros passam a residir na franja urbana, fazendo uso dos modestos meios de consumo coletivos ofertados pela cidade de Altamira (ALONSO e CASTRO, 2006). Na Figura 2, podemos visualizar expansão da malha urbana do município de Altamira e entender a dinâmica de crescimento da cidade de acordo com a construção histórica abordada nesse estudo.

Com base na representação cartográfica da Figura 2 e considerando o processo de formação territorial da cidade de Altamira, é possível identificar três períodos distintos de expansão urbana, a saber:

1960 - 1979: momento de alteração do padrão econômico da região, marcado pela crise da produção extrativista e pelo processo interligação aos eixos viários pela rodovia Transamazônica (BR-230). A expansão urbana é tímida e caracteriza-se pela extensão ao norte em direção ao Igarapé Altamira e ao sudoeste em direção ao recémcriado eixo rodoviário. A área de expansão se conecta diretamente ao centro histórico e novas vias estruturantes são abertas em várias direções, ambas conectadas à BR-230. Algumas dessas áreas estão associadas aos assentamentos instalados pela Prelazia do Xingu nas margens do Igarapé Ambé, com objetivo de evitar um processo de ocupação descontrolada mediante a chegada maciça de migrantes. Houve, inclusive, um levantamento topográfico, a fim de que os lotes não avançassem diretamente para áreas alagadas. Os assentamentos deram origem, em 1973, ao loteamento Nossa Senhora de Aparecida I e, depois, instalaram-se outros, todos em terrenos sujeitos a alagamentos decorrentes das enchentes no Igarapé Ambé. 


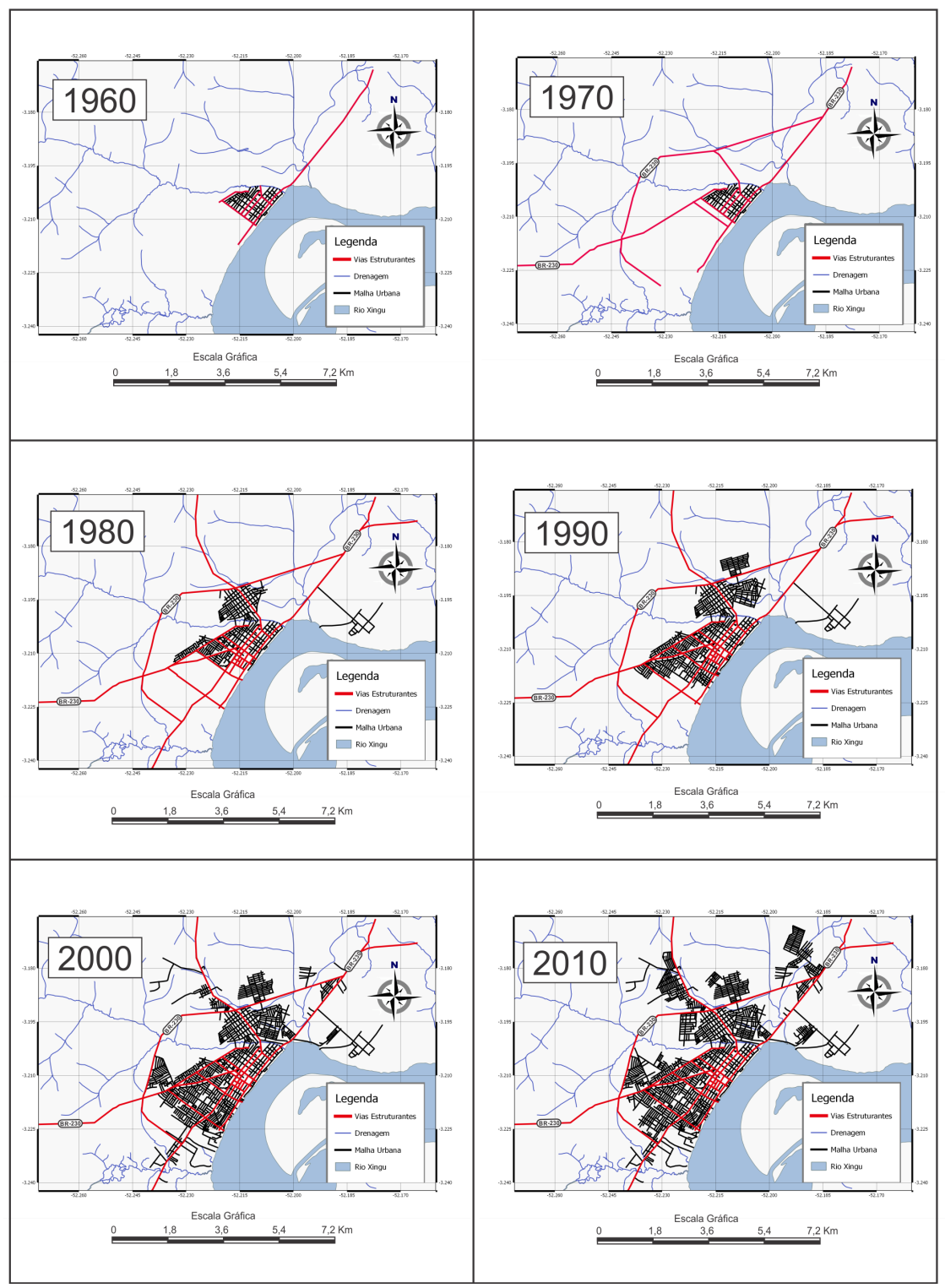

Figura 2. Expansão Urbana da Cidade de Altamira: 1960 - 2010 Fonte: GEDTAM (2014a)

1980 - 1999: período em que a população urbana supera a população rural, com aumento significativo da taxa de urbanização. Aqui a cidade assume o papel de absorver a população migrante das zonas rurais em decorrência da reorientação da política estatal. Como consequência, há o crescimento da malha urbana em várias direções, mas com 
predominância dos eixos estruturantes conectados à BR-230 e aos Igarapés Altamira e Ambé. Muitas dessas áreas estão sujeitas a alagamentos periódicos, conforme o período de cheia do rio Xingu, e os moradores precisam adaptar pontes de acesso para conectar as residências. Em períodos de maior vasão do rio (entre dezembro e março) a cheia chega a 98 metros e atinge as famílias que residem ao longo dos igarapés. Com a diversificação de funções, a cidade consolida seus status de subcentro regional e se destaca na oferta de bens e serviços para as demais cidades de sua hinterlândia. Novos equipamentos urbanos ligados à saúde, lazer, educação e desportos são implantados, porém os sistemas de energia elétrica, abastecimento de água e saneamento continuam precários na maioria dos bairros novos, carentes de infraestrutura e de qualquer planejamento urbanístico. Com a ampliação das funções administrativas e de gestão, muitos funcionários recém-chegados de outras regiões do país começam a se instalar em áreas de absorção da classe média.

2000 - 2010: momento de consolidação do povoamento na região e redução do processo migratório inter-regional para as frentes de expansão. A população rural reduz quase pela metade, ao passo que a população urbana atinge maior ascendência. Como consequência, novos bairros de expansão são criados ao longo dos eixos viários, porém desconectados do centro-histórico num raio de aproximadamente três quilômetros. Esses novos bairros se caracterizam como loteamentos não planejados, sem infraestrutura básica e muitos dos quais sem registro em cartório, a exemplo dos bairros Ibiza, Independente I, Independente II, Bela Vista, Alberto Soares, Liberdade e Colinas. Apesar da carência estrutural, muitas dessas áreas abrigam instalações residenciais de padrão médio, com vistas a absorver a nova população migrante oriunda de diversas regiões do país e motivadas pela oferta de serviços especializados. Porém, a população rural ainda se desloca de forma acelerada para a área urbana, dentre outras razões pelo esvaziamento das opções de crédito agrícola, uma vez que a política de crédito PRONAF não atendeu parte da população rural no período, gerando endividamento e consequente migração. Essa população vai residir em áreas ainda mais precárias, a exemplo da olaria, no igarapé Ambé, com alagamento permanente e cujos únicos acessos se dão por meio de pontes improvisadas e palafitas.

A partir de 2011, com a aprovação da licença de instalação da usina hidrelétrica de Belo Monte, tem-se um marco para o novo período de expansão urbana em Altamira, marcado pela forte especulação de terras e pela atuação das empresas de cunho imobiliário. Em vários pontos da franja rural-urbana se instalam grandes empreendimentos imobiliários com vistas a obter vantagens com a migração em massa de trabalhadores. Nesse momento, a dinâmica da cidade se altera em situação distinta das fases anteriores, fenômeno este que será evidenciado a seguir.

\section{Expansão territorial urbana recente em Altamira}

A dinâmica recente de expansão da cidade de Altamira tem como principal motivador o processo de implantação da Usina Hidrelétrica de Belo Monte no rio Xingu. Com potência instalada de 11.233 MW, estima-se que será a maior usina hidrelétrica inteiramente brasileira e a terceira maior hidrelétrica do mundo. O lago abrangerá uma 
área de $516 \mathrm{~km}^{2}$ e deverá inundar áreas habitadas dos municípios de Altamira, Vitória do Xingu e Brasil Novo.

Com o empreendimento hidrelétrico, a cidade passa por um processo de redefinição urbana, com a requalificação de áreas localizadas às margens dos igarapés e valorização de outras, antes consideradas periféricas no arranjo da cidade. Nesse novo contexto, é importante considerar, por um lado, o papel da Norte Energia S.A (NESA), empresa responsável por gerenciar o empreendimento desde a sua construção até a operação. Por outro lado, cabe destaque ao papel dos agentes públicos no processo de reassentamento e requalificação urbana, a fim de se entender as interferências diretas do empreendimento na estrutura da cidade. A expansão urbana não receberia os contornos atuais, contudo, sem a intervenção dos agentes imobiliários na dinâmica de reorganização do território na área de influência direta do projeto, uma vez que possuem a capacidade de determinar o nível de renda necessário para se ocupar determinados pontos e, ao mesmo tempo, forçar o deslocamento da população para áreas mais periféricas.

Segundo Trindade Júnior \& Rocha (2002) os grandes empreendimentos hidrelétricos são movidos pela lógica da reprodução das relações de produção à escala local e, por isso, "demandam grandes mobilizações de capital, força de trabalho, recursos e energia para sua construção, assim como a urbanização do território como uma condição essencial" (p. 17-18). Considerando essa realidade, a lógica que envolve a área em estudo se caracteriza pela mobilização populacional em massa, pelo aumento atípico da taxa de urbanização, pela ampliação de serviços e equipamentos e pela significativa oferta de lotes urbanizados. Com o empreendimento, espera-se a chegada de mais de 90 mil pessoas para as áreas próximas à obra, grande parte delas destinadas ao núcleo urbano de Altamira.

Neste estudo, identificamos quatro fatores para alteração da dinâmica urbana recente em Altamira, abaixo:

Ações de requalificação urbana: viabilizadas pela Norte Energia no contexto da política de minimização dos impactos, trata-se de um amplo programa de intervenção que abrange o reassentamento urbano, reorganização de parque e da orla e saneamento, que pretende intervir nas cidades de Altamira e Vitória do Xingu e nos núcleos de Belo Monte e Belo Monte do Pontal (NORTE ENERGIA, 2010). As ações visam implantar um conjunto de equipamentos urbanos na cidade, especialmente nas Áreas Diretamente Afetadas no perímetro urbano (ADA Urbana), localizada abaixo da cota altimétrica de 100 metros. Dentre as ações previstas estão à implantação de rede de esgotamento sanitário $(220 \mathrm{~km})$ e o abastecimento de água da cidade $(170 \mathrm{~km})$. Outra ação de requalificação urbana é a criação de parques lineares ao longo dos braços do reservatório do rio Xingu, locais cuja população deve ser retirada e reassentada. Esses parques serão integrados a um sistema de áreas verdes ao longo dos Igarapés Altamira, Ambé e Panelas, abrangendo um total de 512,3 hectares. Tais ações devem alterar mais uma vez a forma urbana de Altamira, uma vez que áreas antes densamente povoadas dão lugar a formas espaciais de uso coletivo.

O processo de Reassentamento urbano: diz respeito à construção de 6.000 unidades habitacionais para populações atingidas e mais 500 casas destinadas a 
trabalhadores. A proposta inicial seria incluir as residências no tecido urbano, evitando com isso a geração de "enclaves" sociais, porém tal possibilidade enfrentou dificuldades pela própria dinâmica especulativa que se acentuou a partir de 2010. Algumas das áreas preferenciais definidas pela Norte Energia para o reassentamento urbano já haviam sido ocupadas por empresas imobiliárias, incorporadoras e usuários particulares. A alternativa de se utilizar dos vazios urbanos também foi descartada, pois os lotes localizados mais próximos ao centro urbano contraíram preços elevados, muitos dos quais foram apropriados por agentes privados para utilização comercial. Assim, das 17 áreas definidas no Projeto Básico Ambiental (PBA) de Belo Monte apenas 3 foram selecionadas com base nos critérios de localização (raio de $2 \mathrm{~km}$ das antigas moradias), acessibilidade (interligação ao sistema viário) bem como as condições topográficas, documentação e condições de aquisição, conforme se pode observar no figura 3. A necessidade de 276 ha para reassentar a população atingida mais 230 ha para abrigar os trabalhadores representa $25 \%$ de toda área urbana ocupada, tornando bem representativo o papel dessas novas residências no contexto de expansão atual.

Ação de grandes empreendimentos imobiliários: é um dos fatores de maior importância no contexto atual. Até 2010, o mercado imobiliário em Altamira não apresentava grandes diferenças em relação às demais cidades de porte médio da Amazônia oriental. Porém, com a liberação das licenças de instalação da UHE Belo Monte, os anos subsequentes se mostraram bem atrativos para esse tipo de negócio. Entre 2011 e 2013 a cidade atingiu o pico dos preços de alugueis e valores para aquisição de imóveis integrados à malha urbana da cidade, fator este que esteve relacionado à presença de mão-de-obra especializada de outras regiões do país para atuar nas primeiras etapas da obra. No mesmo período, proliferam-se vários loteamentos urbanizados situados na franja rural-urbana da cidade, muitos dos quais localizados em antigas fazendas, sítios e lotes rurais localizados em áreas estratégias para o capital extralocal de grande monta. Pela rapidez em que essas áreas foram apropriadas pelas grandes incorporadoras, é possível sugerir a existência de ações antecipatórias pelas empresas no sentido de garantir a aquisição dos terrenos, conforme aponta Souza e Campos (2013) sobre os novos produtos imobiliários nas cidades intermediárias:

Neste caso, os atores extralocais acabam por se articular com os atores locais, firmando parcerias, nas quais esses representam os proprietários de terra e os primeiros ficam responsáveis pela incorporação e construção do empreendimento. Esta articulação dos atores desencadeia a prática da permuta, muito recorrente nessas cidades, na qual os atores locais são proprietários de grandes glebas com potencial para estoque construtivo e possuem interesse em permutá-las pelas unidades habitacionais (lotes) promovidas pelas empresas de fora, que, por sua vez, enxergam nessas cidades um grande potencial de expansão dos seus mercados (p. 12).

Os empreendimentos se instalaram a partir de 2012 e, desde então, alteram as características morfológicas e a paisagem da cidade. O próprio plano urbano de Altamira, marcado por seu traçado ortogonal, dá lugar a novos padrões restritos ao espaço do bairro planejado, como se verifica nos loteamentos Terras de Bonanza, com plano irregular e 
Cidade Jardim, com plano radioconcêntrico. Com utilização da mídia, veicula-se a ideia de bem-estar, acessibilidade e oferta de produtos/serviços, como faculdades e shopping centers. A existência de áreas verdes e amenidades naturais são outros itens importantes para o marketing das empresas. A Tabela 1 apresenta a denominação dos loteamentos instalados na cidade até maio de 2014.

Tabela 1. Lotes urbanizados na cidade de Altamira (2014)

\begin{tabular}{l|l|c|c}
\hline Loteamento & Incorporadora & No de lotes $^{\circ}$ & Hectares \\
\hline Terras de Bonanza & Direção norte incorporadora & 6.615 & 212,17 \\
\hline Cidade Jardim & Buriti empreendimentos Imobiliários & 5.386 & 172,75 \\
\hline Cidade Nova & Nova bairros planejados & 7.000 & 224,00 \\
\hline Viena & Brasil Desenvolvimento Urbano & 2.458 & 78,00 \\
\hline São Francisco & Mac Empreendimentos & 709 & 21,27 \\
\hline TOTAL & 22.168 & 708,19 \\
\hline
\end{tabular}

Fonte: Pesquisa de Campo

Para se ter uma ideia do papel desse novo habitat em relação à malha urbana de 2010 , os 708,19 hectares dos novos loteamentos somados representam um crescimento de $29 \%$ em apenas quatro anos, incrementado sobremaneira o processo de dispersão da cidade.

Ocupação espontânea e intervenção estatal: necessária para a grande massa populacional que não se insere nas condições de renda para adquirir os novos lotes urbanizados. Com a ampliação da fiscalização relacionada à expansão urbana e todo o ambiente legal que se instituiu após a instalação da usina (Lei de Bairros, definição do perímetro urbano, revisão do Plano Diretor e da Lei orgânica Municipal) tornou-se difícil para os pobres adquirirem áreas residenciais na cidade. Até mesmo as áreas de baixo interesse comercial, localizadas às margens dos igarapés, tiveram sua utilização empatada por circunstância dos projetos de requalificação urbana. Por esse motivo, embora se tenha bem definido o local de moradia da nova classe média, ainda não é possível definir com clareza os locais de ocupação espontânea da população de renda mais baixa.

Por receio de que novos bolsões de segregação sejam criados ao longo da cidade, sobretudo a partir da aquisição de terras por meio de invasões, o poder público federal age na criação de unidades habitacionais do Programa Minha Casa Minha Vida. Em 2011 já havia sido instalado 973 lotes, compreendendo 29,19 hectares situados no anel periurbano de Altamira. Em maio de 2013, a Prefeitura autorizou a construção, por parte da Caixa Econômica Federal (CEF), de mais 1.444 unidades habitacionais (43,32 ha) do programa para famílias Faixa 1, com renda máxima de $\mathrm{R} \$ 1.600$ reais, sem necessidade das exigências do programa em nível nacional. O residencial "Ilha do Arapujá" está sendo construído no limite da área urbana de Altamira, próximo à divisa com o município de Vitória do Xingu, com previsão de conclusão em outubro de 2014. Tais iniciativas, contudo, ainda são tímidas diante do déficit de moradia que se apresenta neste aglomerado, especialmente se for considerado o processo de dispensa de mão-deobra previsto para os próximos anos. 
A figura 3 faz a representação da malha urbana atual, destacando as áreas dos novos loteamentos, incluindo aqueles para o segmento de baixa renda do Programa Minha Casa Minha Vida e os construídos para fins de reassentamento populacional.

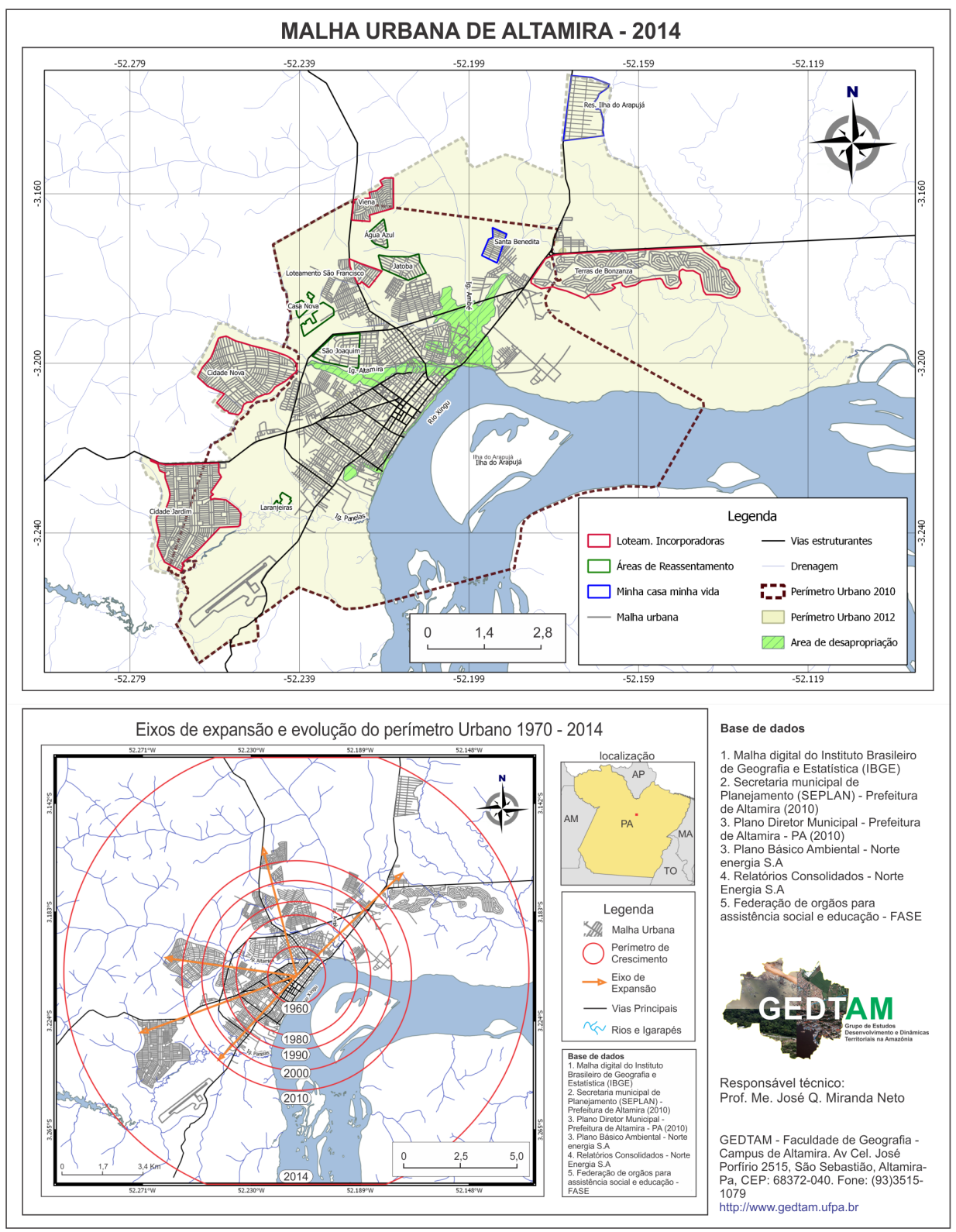

Figura 3. Malha urbana de Altamira - 2014 Fonte: GEDTAM (2014b) 
Com as previsões de alteração do uso de solo urbano, a Prefeitura de Altamira fez a revisão do Plano Diretor em 2010, que define 11 zonas de uso e ocupação do solo da Macrozona urbana I (sede do município). O cenário de referência para a revisão do plano seria de alterações estruturais significativas na área econômica, ambiental, urbanística, sociocultural e político-institucional (Relatório do PDU - Altamira, 2010). Contudo, as previsões de expansão estiveram aquém da realidade no que diz respeito à definição do perímetro urbano, que foi alterado novamente em 2012. Como se pode perceber no figura 3, o antigo perímetro urbano não abrange por completo nenhum dos novos loteamentos, a maioria dos quais criados a partir de 2011. Esse dado é revelador, uma vez que pode indicar o nível de interferência do capital imobiliário de grande monta nas políticas de expansão do município. O perímetro urbano atual, por sua vez, abraça os novos loteamentos como se fosse modelado para dar conta deste novo conteúdo no contexto da cidade.

Outra interferência importante ligada à ação da Prefeitura Municipal diz respeito à necessidade minimização dos vazios urbanos, com vistas a se aproveitar dos benefícios de melhoria da rede. De igual maneira, é necessário agir de forma mais ostensiva em relação ao solo urbano não edificado, subutilizado ou não utilizado, sob o risco de tornar a cidade uma reserva de capital futuro para especuladores imobiliários. No caso de Altamira, já se verifica que a expansão da malha urbana é relativa se comparado ao número de lotes habitados. Em novos loteamentos, por exemplo, embora milhares de terrenos sejam vendidos em dois ou três dias, poucos desses possuem algum tipo de edificação depois de um ano.

\section{Considerações finais}

Não se pode deixar de considerar que a instalação da UHE Belo Monte tem um papel fundamental na estruturação do espaço intraurbano de Altamira. Até 2010, o que se tinha era uma cidade com crescimento urbano médio e previsões de expansão ainda tímidas. Após esse período, especialmente com a introdução de novos agentes privados e com a reorientação dos interesses do poder público, a dinâmica da cidade ganha nova dimensão e chega a superar as expectativas dos próprios planejadores. Atualmente, com as áreas de reassentamento previstas pela Norte Energia e os novos loteamentos das incorporadoras, bem como as ações de habitação da Caixa Econômica Federal, é possível prever um incremento da malha urbana em mais de 50\%. Tal índice toma como referência um período de apenas cinco anos, o que marca a importância de um grande empreendimento hidrelétrico para a conformação atual da forma urbana em uma cidade da Amazônia.

A localização estratégica dos bairros planejados e a ampliação do perímetro urbano por parte da Prefeitura municipal denota um nível de articulação entre o poder público e o capital privado no que se refere ao processo de habitação, o que reafirma a teoria de que o mercado imobiliário cria seu próprio espaço e determina sua localização. Se, por um lado, os novos loteamentos estão bem definidos como o espaço de moradia para a nova classe média, por outro lado a cidade de Altamira se tornou menos acolhedora 
para a população de baixa renda, notadamente pelo acelerado processo de inflação imobiliária. Tal situação exige maior ação por parte do poder público não apenas em criar novas habitações subsidiadas, mas também em fiscalizar com maior rigor a existência de vazios urbanos, de lotes não ocupados ou subutilizados. Nos novos loteamentos, por exemplo, é comum a aquisição de terrenos para a atividade especulativa, o que multiplica os preços e reproduz a escassez.

Por esse motivo, não se pode confundir a expansão da malha urbana com a disponibilidade de terrenos para a massa da população, uma vez que a aquisição destes não representa sua efetiva ocupação. Nestes termos, é possível existir uma crise na habitação em Altamira independente de seu crescimento. Crise esta que pode se acentuar no futuro, uma vez que a partir de 2015, com a conclusão das primeiras etapas da obra, muitos dos trabalhadores que antes residiam em alojamentos próximos ao local de obras devem tentar fixar moradia em Altamira.

Por meio deste trabalho, foi possível perceber o impacto da uma grande hidrelétrica na estruturação interna de uma cidade intermediária, tomando como base o processo de expansão e alteração da forma urbana na cidade de Altamira, principal aglomerado urbano na área de construção da usina hidrelétrica de Belo Monte. A análise dos dados demonstra um crescimento acelerado da malha urbana em várias direções, respeitando o sentido das vias estruturantes. Tal crescimento se dá a partir de novas instalações urbanas para habitação e uso coletivo, públicas e privadas, capazes de alterar significativamente o desenho da cidade, sua paisagem e estrutura urbana. Ressalta-se, contudo, que a metamorfose socioespacial está em pleno curso e outras transformações podem ser notadas, dada a dinâmica acelerada pela qual passa a cidade.

\section{Referências}

ALONSO, S; CASTRO, E. Processo de transformação e representações do rural-urbano em Altamira. In: CARDOSO, A. C. D. O rural e o urbano na Amazônia: diferentes olhares em perspectivas. Belém, ADUFPA, 2006.

BECKER, B. Fronteira e Urbanização repensadas In: Revista Brasileira de Geografia IBGE, 1985. Pp. 357-372.

CASTELlS, M. A questão urbana. Rio de Janeiro, Paz e Terra, 1983.

CLARK, D. Introdução à geografia urbana. São Paulo. Difel, 1985.

CORRÊA, R. L. O Espaço Urbano. 4. Ed. São Paulo: Ática, 2003.

ELETROBRÁS. Meio socioeconômico. In: ELETROBRÁS. CHE Belo Monte: Estudo de impacto ambiental - EIA: Brasília, 2009.

GEDTAM - Grupo de estudos desenvolvimento e dinâmicas territoriais na Amazônia. Expansão Urbana da Cidade de Altamira: 1960 - 2010 [Mapa]. Altamira; 2014ª .

GEDTAM - Grupo de estudos desenvolvimento e dinâmicas territoriais na Amazônia. Malha urbana de Altamira - 2014 [Mapa]. Altamira; 2014b. 
HARVEY, D. A justiça social e a cidade. São Paulo, Hucitec, 1980.

IBGE. Instituto Brasileiro de Geografia e Estatística. Sinopse preliminar do censo demográfico. Rio de Janeiro: IBGE, 2010.

LAMAS, J. M. R. G. Morfologia urbana e desenho da cidade. Porto: Fundação Calouste Gulbenkian/Fundação para a Ciência e a Tecnologia, 2004.

MOUDON, A. V. Urban morphology as an emerging nterdisciplinary field. International Seminar on Urban Form, 1997.

NORTE ENERGIA S.A. Projeto Básico Ambiental da Usina Hidrelétrica de Belo Monte: Planos programas e projetos. Agosto de 2010.

PANDOLFO, C. Amazônia Brasileira: ocupação, desenvolvimento e perspectivas atuais e futuras. Belém: CEJUP, 1994.

SANTOS, M. Manual de Geografia Urbana. 3ed. São Paulo, EDUSP, 2012.

SANTOS, M. A urbanização Brasileira. 5ed. São Paulo: Editora da universidade de São Paulo, 2009.

SOUZA, P. F. e Campos, H. A. Os novos produtos imobiliários em cidades médias brasileiras: um olhar a partir dos circuitos de agentes Produtores do espaço urbano. In: Anais do XV Encontro da associação nacional de Programas de Pós-graduação e Pesquisa em Planejamento urbano e regional, 2013.

TRINDADE JR., S. C.; ROCHA, G. M. (Orgs.). Cidade e empresa na Amazônia: gestão do território e desenvolvimento local. Belém: Paka-Tatu, 2002. P. 13-23.

UMBUZEIRO. A. U. B; UMBUZEIRO, U. M. U. Altamira e sua história. 4ed. Belém, Ponto Press, 2012.

VILLAÇA, F. Espaço intra-urbano no Brasil. São Paulo: Studio Nobel, 2001.

WHITACKER, A. M. \& MIYAZAKI. V. K. O estudo das formas da cidade no âmbito da Geografia Urbana. Anais do $14^{\circ}$ Egal. Peru, 2013.

José QueIroz de Miranda Neto

Doutor em Geografia pela UNESP/Campus de Presidente Prudente, mestre em Geografia pela Universidade Federal do Pará. Atualmente é professor adjunto da Universidade Federal do Pará e compõe o quadro docente da Faculdade de Geografia - UFPA/Campus de Altamira.

Trav. 24 de Dezembro, 88, CEP: 68372-224, Altamira - Pará

E-mail: mirandaneto@ufpa.br 
José ANTÔNIO HERRERA

Doutor em Desenvolvimento econômico, espaço e meio ambiente pela Universidade Estadual de Campinas - UNICAMP. Mestre em agriculturas amazônicas pela Universidade Federal do Pará - UFPA e graduado em ciências agrárias pela Universidade Federal do Pará - UFPA. Atualmente é docente na Faculdade de Geografia do Campus de Altamira e professor do programa de pós-graduação em Geografia (mestrado e doutorado) da Universidade Federal do Pará - Belém / Pará.

Av. Uberaba n 47 Altaville 2 CEP: 68376-080, Altamira - Pará.

E-mail: herrera@ufpa.br

Recebido para publicação em julho de 2015 Aprovado para publicação em novembro de 2016 